\title{
SOBRE TEMPORALIDADE E PLANEJAMENTO DE RECURSOS DIDÁTICOS NO SUBPROJETO DE QUÍMICA - VOLTA REDONDA DO PIBID-UFF
}

Alceu Júnior Paz da Silva ${ }^{\mathrm{i}}$

Denise de Castro Bertagnollii

\begin{abstract}
Resumo: As distintas transformações que caracterizam a sociedade no capitalismo tardio têm sido refletidas em função da noção de tempo. Nesse contexto, a problematização da ideia de tempo nas práticas de planejamento de recursos didáticos em Química, no âmbito do Pibid, apareceu como objeto de investigação. Utilizando aproximações com a teoria HistóricoCultural procuramos orientar a produção/organização de materiais para o ensino de Química por meio da reflexão sobre suas implicações temporais. Como resultado criamos um artefato mobilizador de ideias (esqueleto de peixe) para a construção de propostas pedagógicas temáticas em Química, voltadas ao Ensino Médio.
\end{abstract}

Palavras-chave: Noções de tempo; Teoria Histórico-Cultural; Recursos Didáticos; Educação em Química.

\section{ABOUT TEMPORALITY AND DIDACTIC RESOURCE PLANNING IN THE PIBID- UFF'S CHEMISTRY SUBPROJECT PLACED IN VOLTA REDONDA}

\begin{abstract}
Different changes that characterize society in late capitalism have been reflected in terms of the notion of time. In this context, the questioning of the idea of time in the planning practices of didactic resources in Chemistry under the Pibid project appeared as a research object. Using an approach inspired in historical-cultural theory we seek to guide the production and the organizing of materials for chemistry teaching through reflection on its temporal implications. As a result, we have created a mobilizer artifact of ideas (fish skeleton) to construct thematic educational proposals, aimed at high school's Chemistry.
\end{abstract}

Key-words: Notions of time; Historical-Cultural Theory; Didactic Resources, Chemical Education.

\section{Do tempo na sociedade a sociedade do tempo}

A escola atual ainda tem como suas aspirações a obsessão por controlar o tempo e o movimento, como postulava Frederick Winslow Taylor em seus estudos com trabalhadores na Midvale Steel Works. Dividir o processo em etapas padronizadas, transformando-as em um conjunto de regras, para aumentar a eficiência. $\mathrm{O}$ cronômetro pressupunha aprisionar toda a ação à vigilância e à padronização. Os sistemas tecnológicos modernos não fogem a essas raízes 
de controle do tempo e, em especial, à dicotomia entre concepção (pequeno grupo) e execução (operários) de produtos ou processos (SINGER, 1994).

Diante dessa mecanicidade temporal que tem caracterizado a organização dos processos de sala de aula (um tempo saerjial ${ }^{\mathrm{iii}}$ ) procuramos evidências sobre a centralidade do tempo na sociedade contemporânea, uma vez que, os processos de escolarização e os educacionais (sentido lato) vividos na sociedade em geral interagem, transformam-se.

Para Gilles Lipovetsky (obra original de 2004), a perda das expectativas de futuro e o "encurtamento" do processo histórico (reduzido ao cotidiano e ao efêmero, ou seja, a uma temporalidade do aqui agora) em decorrência do consumismo e da comunicação de massas não chegou, pois estamos vivenciando mais a radicalização da modernidade que a sua superação. Então, o tempo se apresenta numa sociedade moda, uma sociedade hipermoderna marcada pelos excessos comportamentais individuais, numa convulsão do "sempre mais", isto é, um hiperindividualismo nucleado pelo princípio moda, uma paixão cotidiana pelo novo e seus modos de vida. Essa temporalidade da moda ou frenesi ritmado pelo consumismo plasma o tempo no presente sempre revigorado pela opção de uma nova compra (neofilia). O tempo passa a ser urgente. Nessa cultura hedonista individualista, “(a) primazia do presente se instalou menos pela ausência (de sentido, de valor, de projeto histórico) que pelo excesso (de bens, de imagens, de solicitações hedonistas)" (LIPOVETSKY, 2004, p. 60-61). As revoluções no campo da informática, a partir dos anos de 1990, elevaram essa compressão do tempo, quando "a mídia eletrônica e informática possibilita a informação e os intercâmbios em 'tempo real', criando uma sensação de simultaneidade e de imediatez que desvaloriza sempre mais as formas de espera e lentidão" (LIPOVETSKY, 2004, p. 62-63).

Mas o que difere Lipovetsky da leitura pós-moderna do presentismo é que o mesmo encontra-se posto de forma paradoxal. As agruras decorrentes do hipercapitalismo, como desemprego, pobreza, instabilidade empregatícia, catástrofes, terrorismo, guerras, etc., trouxeram a insegurança e a incerteza para seu núcleo presentista. Ressalta o autor que, de "um lado, a sociedade moda não pára de instigar aos gozos já reduzidos do consumo, do lazer e do bem-estar. De outro, a vida fica menos frívola, mais estressante, mais apreensiva" (LIPOVETSKY, 2004, p. 64-65).

Esse paradoxo é a chave para Lipovetsky se distinguir de um retrato orwelliano de presente absoluto perpétuo, fechado em si mesmo, distante do presente e do passado. Mas o que difere na sua leitura do presentismo é o fato de ele, impulsionado pelas suas tensões paradoxais, 
encontrar-se ampliado. O excesso e o consumo nele se movimentam para preencher o passado (revisitado e integrado ao novo ritmo) e o futuro (incerto e precário). O encurtamento, entretanto, não suprime o futuro, apesar de diminuir sua força. Como exemplo toma a perseguição excessiva pela saúde e a longevidade, sob a qual "os indivíduos renunciam maciçamente às satisfações imediatas, corrigindo e reorientando seus comportamentos cotidianos" (LIPOVETSKY, 2004, p. 73), o que hoje poderíamos pensar como Angelina Jolie Síndrome. A Ciência é promessa de um mundo melhor quanto de catástrofes.

Saindo dos limites daquele tempo de trabalho e penetrando na vida cotidiana, temos, ainda, duas características marcantes, que são as temporalidades heterogêneas e a diminuição do tempo social. O uso do tempo se personalizou mediante o hipermercado da moda (e seus estilos de vida) e, escapando aos "entraves" do tempo coletivo (compartilhado / de interação social), promoveu "uma dessincronização das atividades, dos ritmos e trajetórias individuais" (LIPOVETSKY, 2004, p. 78), sem perder de vista o lema: “Quanto mais depressa se vai, menos tempo se tem", o qual perpassa faixas etárias e estratos sociais.

A negação do cenário consumista como um comportamento simplesmente imposto de forma totalitária, e que leva esse autor a recusar que o mesmo seja “(...) o reflexo fiel das lógicas hiperbólicas midiático-mercantis (, nem) produto mecânico da publicidade" (LIPOVETSKY, 2004, p. 81), é o ponto de partida para inserirmos a análise de Benjamin Barber (obra original de 2007), igualmente, recortando sua noção de tempo. Partindo da análise da dimensão do consumo no capitalismo, e como condição de sua sobrevivência, o autor investiga as estratégias contemporâneas para universalizar a vontade de consumir, não apenas abrangendo todos os espaços geográficos, mas, sobretudo, todo o tempo.

Nessa empreitada, cria-se a necessidade de uma homogeneização dos gostos para o consumo de mercadorias uniformes, entrando em cena um etos infantilista que estende, para ambos os lados, a linha divisória entre criança e adulto, pois, infância induzida é infância vitalícia. $\mathrm{O}$ autor baseia-se nas escaladas de ações das corporações no âmbito do marketing (não apenas destinadas a bebês e às crianças) como movimento de infantilização do próprio adulto. Em meio a uma estupidificação pop-cultural e fílmica (frivolidades de celebridades e esportistas) Hollywood precisa, para o consumo de seus blockbusters, de "pessoas com uma capacidade subdesenvolvida de gratificação posterior, ou seja, crianças” (BARBER, 2009, p. $38)$. 
Sem intencionar reduzir sua obra, recortando-a, tomamos do consumismo a dualidade rápido-lento e a onipresença como categorias para pensar o tempo sob o etos infantilista. Ambas são mais elementos "suaves de manipulação escondido por seu caráter liberal (capitalismo de consumo)" do que de imposições totalitárias, mas que trazem implicações para o exercício da democracia. Em resumo, a onipresença reside no fato de que o mercado não apenas procura ocupar radicalmente todo o espaço possível, mas, também, todo o tempo.

Com o controle do tempo pela mídia, o marketing se encarrega de captar indivíduos com déficit de atenção ao "estupidificar, acelerar e fazer cortes rápidos (em seus conteúdos) priorizando a velocidade e uma preferência pela repetição" (BARBER, 2009, p. 261), por outro lado, apoiado pelas múltiplas tecnologias, elástico fica o tempo, quando tarefas feitas simultaneamente encurtam para minutos para aquilo que, antes, eram necessárias horas, isto é, surgem mais horas no relógio. O tempo de consumo é prontamente alterado. Se antes, a tela de TV servira para abrir buracos em nossa rotina cotidiana, hoje, os celulares, e suas pequenas telas, preenchem os buracos restantes de nossos intervalos de, espera de ônibus, trem, de consulta médica, em filas, banheiro, no fast food, etc., ou seja, hoje "não há lugar algum para se esconder: o iPod e o telefone celular, a internet sem fio e o tele cosmo estão em toda parte com você. Já não há momento algum para encontrar um refúgio; o tempo pertence ao mercado" (BARBER, 2009, p. 264).

Na caracterização do etos infantilista, inspirado em Neil Postman, Barber traz, entre outras, a dualidade rápido-lento para pensar as dimensões do adulto e da criança, mas sem antagonizá-las, apresentando no comportamento infantilizado a sobreposição da rapidez sobre a lentidão. Comida, música, edição de filmes, computadores, atletismo, fornos, congelamento, conversas e crédito rápidos-instantâneos, “(...) induzidos pela mídia(,) pedem essa velocidade (e sendo uma) droga como qualquer outra, (...) tem de ser tomada em doses cada vez mais elevadas para manter seu efeito sobre a psique" (BARBER, 2009, p. 116).

Algumas ilustrações apontadas são: i) a digitalização facilita uma ruptura artificial com a nossa percepção da linearidade do tempo ao mostrá-lo fragmentado e não sequencial; ii) as mensagens instantâneas economizam horas de comunicação que não são convertidas em exploração pessoal da língua materna por meio do exercício da escrita; iii) os jogos digitais em alta velocidade ativam sinapses pré-existentes restringindo o pensamento a forma associativa rápida, não a novas formações sinápticas; iv) comunicação instantânea por celular e internet restringem as interações em espaços sociais e públicos; v) um déficit de atenção induzido 
promove a dissuasão de concentração e a não continuidade; vi) a preferência pelo rápido gera afinidades por formas políticas específicas (interfere na escolha); vii) favorece comportamentos individuais, comuns mas não previamente deliberados (refletidos coletivamente, uma ideologia dos "direitos individuais"); viii) como ideologia, rejeita a ética da obrigação e da responsabilidade que o remete a sociabilidade ("o dever com os outros")" (BARBER, 2009, p. 117-126).

De outra matriz, temos uma instigante leitura sobre tempo de Crary (obra original de 2014) que nos remete ao sono, como sendo a última barreira a ser superada pelo capitalismo. $\mathrm{O}$ ponto de chegada de Barber, a insuficiência de horas contidas num dia para os fins do mercado, no qual o marketing nos diz que, "explorando as típicas multitarefas dos jovens acelerados é possível levar 'membros da geração Minha Mídia' (a) se adequar a mais de 44 horas de atividade em apenas um dia” (BARBER, 2009, p. 261), é o ponto de partida de Crary.

Atento aos movimentos do complexo científico-industrial-militar norte-americano, Crary parte das pesquisas recentes realizadas nos últimos 7 anos e financiadas pelos EUA sobre a atividade cerebral dos pardais de coroa branca, uma vez que, durante as migrações (do Alaska ao norte do México) eles são capazes de ficar sete dias sem dormir. Nos moldes daquele complexo, os esforços de pesquisa têm sua gênese no campo militar ao ensejarem potencializar a eficiência de soldados, pois o sonho de uma guerra totalmente automatizada (Drones, ataques à distância, etc.) tem se mostrado irrealizável.

Traz o autor a informação de que, inspirado pelas pesquisas do Pentágono (Darpa)

(,) cientistas estão conduzindo testes experimentais de técnicas de privação de sono em diversos laboratórios, incluindo substâncias neuroquímicas, terapia genética e estimulação magnética transcraniana (...) (,) em curto prazo (...)(intencionam fazer) um combatente ficar sem dormir por, pelo menos, sete dias (,) ao longo prazo, duplicar(,) (...) preservando alto nível de desempenho mental e físico (CRARY, 2014, p. 07).

A grande questão científica que Crary traz à tona é o desafio de reduzir a necessidade do sono do corpo sem perder, com isso, potencial produtivo, ao contrário dos distúrbios psíquicos que podem acontecer quando a insônia é induzida. O estímulo à vigília, por meio de drogas, tem sido recorrente (Provigil, Ritalina, etc.) entre profissionais, executivos, estudantes e soldados em guerra (Captagon). Aqui, o autor questiona se a disponibilização no mercado de possíveis drogas redutoras do sono não seriam prontamente consumidas? Ou, conforme Barber 
e Lipovetsky, assumindo a identidade dessas marcas ou agregando-se ao estilo de vida. Em outras palavras: do soldado sem sono a um consumidor sem sono.

O ponto fundamental de sua expressão $24 / 7$ (24 horas por 7 dias da semana) não é apenas o reconhecimento, há décadas, do trabalho e do mercado de consumo globais nessa temporalidade 24/7, mas, sobretudo, um movimento para "fazê-los coincidir mais intensamente" com o ser humano. Nesse sentido, a temporalidade 24/7 não é homogênea, vazia e linear, mas acaba desprivilegiando tarefas de longo prazo (como progresso e desenvolvimento). Isso sugere que tenhamos que ver o sono como resistência, uma vez que, em "sua inutilidade profunda e passividade intrínseca, com as perdas incalculáveis que causa ao tempo produtivo, à circulação e ao consumo, o sono sempre estará a contrapelo das demandas de um universo 24/7" (CRARY, 2014, p. 13-14).

Cita pesquisas que retratam o aumento dos casos de pessoas que acordam mais de uma vez à noite para verificar mensagens, sendo que, a expressão "sleep mode", reflete a lógica do não completamente "desligado" (dormindo), mas em estado de sono diminuído, não pleno. Exorta que, atualmente, são "pouquíssimos interlúdios significativos na existência humana (com a exceção colossal do sono) que não tenham sido permeados ou apropriados pelo tempo de trabalho, pelo consumo ou pelo marketing" (CRARY, 2014, p. 16).

Uma vez que o sono aparece como obstáculo último ao capitalismo, sua não supressão total aparece na forma de tentativas de sua precarização, a qual, como efeito rebote, implica na sua compra. Se a Ritalina estimula a vigília, o aumento no consumo de barbitúricos permite a aquisição do quase-sono, quimicamente induzido. Espaços públicos são projetados para impedir o sono (como nas formas serrilhadas de bancos e assemelhados), simbolizando que sua garantia (sentido lato), também passa pelo público. Nessa reflexão, uma pedagogia do sono sintetiza-se no fato de que, "no contexto de nosso próprio presente, o sono pode representar a durabilidade do social, e que o sono pode ser análogo a outros limiares nos quais a sociedade poderia defender ou proteger-se a si mesma. Como o estado mais privado e vulnerável de todos, o sono depende crucialmente da sociedade para se sustentar" (CRARY, 2014, p. 24).

Essas três abordagens nos ajudam a ilustrar a relevância que a noção de tempo tem nas análises sobre a sociedade contemporânea. Se as raízes do projeto taylorista emergem na escola brasileira, como esses fenômenos que caracterizam a sociedade em função do tempo nela se confrontam? 
Como vimos, essas diferentes leituras nos mostram um tempo forjado no e para o capitalismo de consumo, o qual, orientado pelos prazeres individualistas, desvaloriza o tempo de interação social, supervaloriza a rapidez e a repetição (pensamento associativo/dissuasão da concentração), ofusca perspectivas de futuro como projetos históricos (e de sociedade), se universaliza como tempo de marketing e é apresentado de forma fragmentada.

O funk de ostentação (como expressão de uma temporalidade da moda ou do etos infantilista) e o uso corrente de celulares com acesso à internet são lugar comum na vida cotidiana de nossos adolescentes. O contato com múltiplos tipos de mídias, o uso de computadores e games, a comunicação instantânea e o ativismo em redes sociais são aspectos que nos fazem considerar como a percepção do "tempo fora da escola" constrange/possibilita as intencionalidades pedagógicas no "tempo dentro da escola".

Nesse caminho, ao voltarmos o nosso olhar para o planejamento de ensino constatamos sua dimensão temporal, por um lado, em propostas metodológicas, dos momentos pedagógicos (Delizoicov e Angotti, 1990) às atividades-chaves (Carvalho, 2013), as diferentes funções pedagógicas de cada "etapa" pressupõem sua localização temporal, mesmo não se propondo como estruturas rígidas, mecânicas e deterministas, momentos de motivação, de mediação na construção de conceitos e atitudes e de uso autônomo do objeto de aprendizagem carecem desse tempo refletido o qual, ao se afastar do tempo de consumo (rápido/descontínuo), não reduz o planejamento de ensino à mera receita pronta e infalível.

Por outro, os princípios metodológicos se materializam em ações e artefatos pedagógicos. Se o campo das Ciências Naturais mobiliza no seu fazer diferentes noções de tempo (a duração de: uma reação química, um movimento humano, uma transformação geológica, um fenômeno cosmológico), Lemke (2000), depois de nos dizer que essas escalas de tempo são relativamente interdependentes, vai colocar na mediação semiótica (por meio de artefatos semióticos materiais) o ponto de ligação/interação através dessas diferentes escalas de tempo.

Se a onipresença do tempo de consumo se efetivou por meio da internet e seus veículos (de tablet a smartphone), para o autor, essas diferentes mídias não se limitam a ligar um produtor a seu usuário, mas a ligar esse último através de escalas de tempo de produção, circulação e uso, sendo que, a construção de significados (e a experiência) no trabalho com mídia pode nos dizer quais e como as escalas de tempo estão (ou não estão) conectadas ou integradas (LEMKE, 2009, p. 143). 
Em sala de aula, os diversos recursos didáticos e ações também funcionam como artefatos mediadores de noções de tempo. Se um simples caderno de anotações dos alunos os ajuda em tarefas escolares semanais, o discurso do professor sobre reações químicas mediado pelo livro didático tem a marca (e é síntese) de um longo processo histórico dessa Ciência e desse para o das editoras de livros. Dessa forma, processos de longo tempo se conectam/afetam eventos de curto tempo mediado por um objeto (material e semioticamente) (LEMKE, 2000, p. 281-282).

Dessa forma, a multimodalidade vivenciada no ensino de Química nos revela que a construção de significados perpassa por distintos modos de mediação, verbal e não-verbal, envolvendo fala, escrita, gesto, gráfico, tato, mímica, pictórico, visualização em 3D, etc., (integrados entre si) e vinculados à distintos recursos didáticos (não se restringindo ao livro didático e ao quadro-verde) tais como experimentos, animações, simulações, vídeos, imagens estáticas em 2D, representações em 3D, textos escritos, fichas de anotações, etc.

Esses aspectos nos fomentam a necessidade de pensar a localização temporal do uso desses artefatos mediadores, não apenas explorando suas potencialidades em ligar/perceber as escalas de tempo e em operacionalizar o tempo de sala de aula, mas, direcionar seus atributos para o confronto com o tempo de consumo e não para a sua legitimação.

Em nosso caso particular, recortamos o tema com o seguinte questionamento: Em que medida é promissora a problematização das relações temporais no processo de planejamento de recursos didáticos em Química? Como podemos mediar essa tarefa no contexto da formação inicial de professores, isto é, na prática de pibidianos imersos no ambiente de sala de aula das escolas públicas do Estado do Rio de Janeiro?

\section{Nos primeiros passos, uma aproximação com a Teoria Histórico-Cultural.}

Ao nos movimentarmos nos dilemas e desafios do presente na companhia da Teoria Histórico-Cultural, cabe ressaltar que a construção teórica de Vigotski foi originalmente gestada num outro tempo, no da Revolução Russa, marcada pela guerra, pela insurreição e por transformações rápidas, do ponto de vista histórico, e intensas, do ponto de vista político. Sua relação inicial com a escola soviética nascente englobava a educação, tanto de crianças, quanto de jovens marginalizados, que falavam mais a partir da dinâmica das ruas que de uma escola que fora objeto de privação. Contudo, seu vigor persiste conforme panorama de pesquisas 
descrito por Daniels: “Os próprios textos originais são ricos e complexos. Fornecem uma multiplicidade de vias estimulantes de exploração e desenvolvimento" (DANIELS, 2011, p. $11)$.

Em que pode residir a potencialidade da perspectiva vigotskiana nos debates sobre o tempo? Sua inserção cai numa histórica aporia, na qual, de um lado se evoca um "tempo objetivo" (ligado à natureza, ao mundo cosmológico ou físico, ou seja, às Ciências) e, de outro, temos a defesa de um "tempo subjetivo" (ligado à consciência, ao psicológico ou fenomenológico, ou seja, às vivências), conforme Carvalho (2012, p. 01). Essa aporia tem assumido (ou se expressado) em distintas dicotomias, como tempos: quantitativo e qualitativo; real e imaginário; natural e cultural; físico e social; e, comumente, representada pelos termos gregos chronos e kairos (de origem mitológica, ilustram os aspectos quantitativo e qualitativo) (CARVALHO, 2012, p. 4-5).

Nesse contexto, o da "solução" dessa aporia, tem sido explorado o trabalho do sociólogo alemão Norbert Elias em seu livro Sobre o tempo (Über die zeit) (obra original de 1984), no qual, tem em projeto criar as trilhas para a superação de abordagens reducionistas sobre tempo, ora, subjetivistas, ora, objetivistas. Na história da Filosofia, de forma sucinta, Abbagnano (2007, p. 945-947) nos apresenta aspectos dessa dualidade em três vertentes: tempo mensurável de origem pitagórica e defendida por Aristóteles (seguido por: Newton, Leibniz, Kant e Einstein); tempo como intuição do movimento, residente na consciência e expresso por Santo Agostinho (seguido por: Bergson, Husserl) e tempo como estrutura das possibilidades, trazido por Heidegger, o qual, ao contrário das anteriores, que têm o primado do presente, mostra o primado do futuro na interpretação do tempo.

O motivo de trazermos Norbert Elias, primeiro, como fonte de estudo e, segundo, como fonte de exploração para o suporte de uma leitura vigotskiana do tempo, expressa-se em suas ideias chaves. Ao enfatizar o porque da necessidade de se determinar o tempo, o autor não se limita a indagar apenas o que é o tempo? Na medida em que, a primeira o remete a uma abordagem evolutiva, isto é, no olhar para a história das civilizações e suas respectivas relações com o fenômeno do tempo. Somam-se a esse pressuposto, de que o conhecimento do tempo resulta de "um longo processo de aprendizagem” (ELIAS, 1998, p. 10), o de sua natureza simbólica e de alto nível de síntese, em estágios atuais. Ilustra o autor que, ao

(...) constatar, por exemplo, que é meio-dia do décimo segundo dia do décimo segundo mês do ano de 1212, fixamos, simultaneamente, um marco temporal 
no fluxo de uma vida individual, na evolução de uma sociedade e no devir da natureza. (...) (R)elaciona posições que se situam, respectivamente, na sucessão dos eventos físicos, no movimento da sociedade e no curso de uma vida individual (ELIAS, 1998, p. 17).

O seu alto nível de síntese leva a uma compreensão ampla do tempo, alicerçada na interdependência do físico, do social e do individual, e necessária à superação daqueles reducionismos dualistas. Em fluxo contínuo e emergidos do universo quadrimensional (espaço e tempo), os movimentos do Sol (independentes da ação humana) ou dos ponteiros de um relógio (moldados pela ação humana) "são exemplos de sequências recorrentes que podem servir como unidades de referência e meios de comparação para segmentos de processos pertencentes a uma outra série e que não podem ser diretamente relacionados, em razão de seu caráter sucessivo" (ELIAS, 1998, p. 13 - grifos nossos).

A necessidade e o ato de comparar-relacionar aspectos de distintas sequências de acontecimentos perceptíveis fazem emergir a sua natureza simbólica (ou mediacional, para Vigotski), produzindo unidades de significação do tempo (“um símbolo social comunicável”) e, com isso, o colocando num universo tornado quinquedimensional, ou seja, acrescido da dimensão humana e servindo de meio de orientação no fluxo desse mesmo devir físico-socialindividual. Na função de comunicação faz com que "imagens mnêmicas" possam ser compartilhadas e assumam no indivíduo uma experiência singular, ou melhor, uma individualização de aspectos sociais objetivos.

Uma vez que, a referida obra complementa seus estudos anteriores, vemos no tempo as marcas de um Processo Civilizador. Como advento social, o tempo exerce poder coercitivo sobre as consciências singulares e autônomas forjando a personalidade, em outras palavras, exemplifica o "problema do equilíbrio entre autodisciplina individual e restrição (coerção) social externa" (ELIAS, 1998, p. 30). Próximo à ideia vigotskiana de mediação, Elias percebe que, num passo adiante, para além da comunicação, o tempo em sua natureza simbólica (associado a um "símbolo social móvel"), e oriundo de instrumentos físicos de determinação, exerce função de regulador das condutas individual e social e da sensibilidade.

Num segundo passo, a aproximação com L. S. Vigotski, se dá ao reconhecer os símbolos linguísticos na construção de conhecimento, patrimônio social e transmissível historicamente por meio da aprendizagem, ao passo que, sociologicamente, expressa que não antagoniza saber e conhecimento, pois, “a operação individual de cognição numa pessoa é inseparável do saber 
que ela adquiriu junto a outras, e portanto, no final das contas, do nível de desenvolvimento atingido pelo patrimônio de saber da sociedade. Quem não sabe nada não pode atestar cognição" (ELIAS, 1998, p. 27 - Nota 2). A mesma abordagem não antagônica vemos em Vigotski entre Conceitos Cotidianos e Conceitos Científicos.

O terceiro passo adiante, aqui recortado, se dá no reconhecimento das implicações afetivas da língua (no Capítulo 7: Pensamento e palavra, ao sair do lugar "seguro" do significado ao "inseguro" do sentido, por meio do subtexto teatral, um retorno ao Hamlet e a Psicologia da Arte), também reconhecida, ainda que não desenvolvida teoricamente, por Vigotski, em seu ensaio Teoria das Emoções (VIGOTSKY, 2004), em suas palavras, "não podemos descartar a ideia de que a humanidade venha a conhecer uma situação em que os símbolos sociais ligados a uma atividade de pensamento, de linguagem e de conhecimento altamente distanciada transformem-se em símbolos marcados por uma intensa implicação emocional" (ELIAS, 1998, p. 28 - grifo nosso).

Sintetiza Elias que, dessa forma,

(o) mostrador do relógio de uma estação ferroviária evidencia que, nesse caso, estamos lidando com um instrumento de orientação institucionalizado no plano social. O mecanismo desse relógio, que funciona continuamente e de maneira bem determinada, dirige uma mensagem visual institucionalizada a qualquer pessoa capaz de associar a esse motivo visual o motivo mnêmico que convém. Por fim, à função de meio de orientação exercida pelo tempo vem juntar-se (a) de instrumento de regulação da conduta e da sensibilidade humanas (ELIAS, 1998, p. 30).

Esses aspectos gerais, do trabalho do autor, não nos permitem reduzir sua análise e seu legado, mas ao contrário, nos auxiliaram a uma primeira aproximação teórica, assim como, a articulação do problema do tempo com L. S. Vigotski vem, igualmente, estimulada pela densidade e pela incompletude da obra do pensador soviético.

O ponto nodal, que escolhemos, foi o de que Elias e Vigotski rejeitam o antagonismo entre natureza subjetiva e objetiva, respectivamente, do tempo e do desenvolvimento humano. Em L. S. Vigotski, a categoria mediação fugirá de abordagens dicotômicas de base mecânica e determinista da relação entre indivíduo e sociedade (ou papel do simbólico para Elias). O sujeito interage-transforma o seu contexto mediado por artefatos culturais ao mesmo tempo em que se torna objeto de transformação desse mesmo ambiente mediatizado. 


\section{Uma pedagogia antropoide nos processos de escolarização}

As relações e as interações entre o pensamento e a fala mostram de pronto uma concepção mais fluídica e complexa (e em unidade) que estruturalista. Tanto na ontogênese quanto na filogênese suas linhas de desenvolvimento podem divergir, convergir, cruzar-se, nivelar-se paralelamente, confluir e, novamente, bifurcar-se, preservando suas distintas origens. Vigotski traz dos estudos sobre o macaco antropoide, no qual a sua semelhança com o homem se localiza sobre a sua capacidade em criar instrumentos e realizar tarefas, uma vez que, baseado num intelecto relativamente desenvolvido, dispõe de uma inteligência prática. Por outro lado, apresenta uma pré-linguagem, marcada pela ausência de representações e mesmo mostrando capacidade de comunicação baseada em sons, mímicas e gestos, essa fica presa ao campo da emoção e da vontade (linguagem emocional).

Encontram-se aí as origens e a base para o desenvolvimento da fala humana, nesses rudimentos emocionais que se sobrepunham a possibilidade de uma fala objetiva-intelectual. Em seu tempo, Vigotski demarca nesses estudos a limitação do comportamento antropoide ao seu campo visual (aquelas tarefas apenas eram realizadas baseadas em objetos passíveis de visualização) e a sua restrição na capacidade ideação (criação de imagens), ou seja, na capacidade de operar com resíduos de estímulos não atuais e ausentes (no máximo, semelhante a uma criança de três anos).

Sobretudo, destacamos a ausência da produção de cultura que pressupõe a capacidade de ensinar, pois ninguém jamais pode verificar entre os macacos antropoides nenhum instrumento, que como os dos humanos, “(...) variam de tribo para tribo, mas que atestam a transmissão das descobertas de geração para geração (e) nenhum rabisco sobre arenito ou argila que pudesse ser tomando por desenho representando algo (...)" (Bühler apud Vigotski, 2009, p. 117).

Embora, nas salas de aula atuais, e nas do Estado do Rio de Janeiro, em particular, encontremos adolescentes ou jovens, com suas funções psicológicas superiores desenvolvidas e imersos na vida contemporânea tecnologizada e informatizada (como apontadas, anteriormente, por Barber, Lipovetsky e Crary), por vezes, professores e futuros professores reproduzem frases do tipo: Os alunos são imaturos! Não se pode elevar o nível de exigência senão eles não acompanham o programa! Esse conceito é muito abstrato para eles! Existe muita matemática e eles não têm base! Não sabem ler, interpretar! 
Se o mundo "fora" da escola, o qual "aparece" sempre como promissor-provedor do desenvolvimento cultural, pode estar orientado por práticas que privilegiam o rápido e o fácil, as mesmas "aparências" de limitações intelectuais podem ser desveladas no mundo escolar. Em outras palavras, ao nos voltarmos para as práticas de ensinagem (escolares), até que ponto vemos um ensino pré-behaviorista se processando? Em que medida se reduz e se fixa o material de ensino às suas possibilidades como campo visual e não o localiza no campo do pensamento? Estaria orientado rumo às formas sucessivas ideações, pertinentes a formação de conceitos?

Nesse contexto, a defesa da escolaridade por Vigotski reverbera como dispositivo fundamental de acesso aos sistemas de conceitos, ou seja, aos conceitos científicos-escolares. Acesso que vai ser materializado, estrategicamente, pelo fato de a instrução e o desenvolvimento se colocarem, dialeticamente, sob a ideia de Zona de Desenvolvimento Iminente (ZDI) (PRESTES, 2010), sendo ela, a “discrepância entre a idade mental real ou nível de desenvolvimento atual, que é definida com o auxílio dos problemas resolvidos com autonomia, e o nível que ela atinge ao resolver problemas sem autonomia, em colaboração com outra pessoa" (VIGOTSKI, 2009, p. 327). Algumas leituras apontam para uma diferenciação, isto é, para o uso de scaffolding (no lugar de ZDI) quando se tratar de ensino de conceitos ou habilidades específicas, conforme Chaiklin (2003, p. 59).

Essa ação colaborativa, em nosso caso, estabelecida pelo futuro professor de Química, vai apresentar os sistemas de conceitos necessários ou pertinentes ao desenvolvimento do educando a qual, de imediato, deverá estar orientada (planejamento de ensino) não tanto para o que os alunos já sabem, quanto para o que poderiam vir a aprender. Importante constatação no contexto atual, ou seja, o encurtamento do tempo de acesso a conhecimentos e informações pela internet, por parte dos alunos, não se coloca antagonicamente à ação mediadora do professor, uma vez que, a própria ZDI (ou scaffolding) pode se "deslocar" para níveis ulteriores (mediada pela elevação do nível de problemas apresentados), fundamentais para que os significados se desenvolvam como síntese de uma totalidade complexa. Um desenvolvimento mútuo da unidade formada por conceitos cotidianos (CCot) e conceitos científicos (CCie).

Se os primeiros experimentos foram focados no intramental, caracterizando o movimento dos pensamentos sincrético, por complexos e conceitual, os segundos foram focados no intermental, na esteira dos CCie (sistêmicos e de alta abstração e generalidade), típicos da instrução escolar, e os CCot (generalização simples e rica em sua concretude) formados no contexto da prática social imediata. Aqui, temos que os CCot medeiam a relação 
entre os CCie e o sujeito, o que impede a efetivação da aprendizagem por transmissão direta de conceitos científicos (VIGOTSKI, 2009, p. 269).

Demarcar o papel dos CCot num contexto de ensino marcado pelo associacionismo de palavras vazias de significado e fortemente centrado no aspecto visual concreto (é comum encontrarmos expressões do tipo: é para os alunos poderem "visualizar" os conceitos da Química! Muito embora não possamos enxergar átomos e moléculas) torna-se relevante para uma crítica às perspectivas de ensinagem centradas e essencializadas no indivíduo (e não na interação) e no seu "auto-suficiente-desenvolvimento", uma vez que, os CCie não apenas reestruturam os CCot e os fazem se desenvolver por criarem uma ZDI entre eles, mas, sobretudo, por serem ferramentas mediadoras do pensamento na resolução de problemas em domínios subjetivos. Em linhas desenvolvimentais distintas (CCie e CCot), a aprendizagem do primeiro é impulsionada pelo segundo, porém, num processo que está longe de se dar por elaboração e refinamento dos CCot.

Em outras palavras, o acúmulo de informações obtidas pela prática cotidiana ou por fontes variadas não é garantia absoluta de que o adolescente apreenda e desenvolva de per si conceitos científicos, ainda que, em última análise, se dê por reconstrução criativa, mas é na riqueza das interações professor-alunos que o seu carácter voluntário, a sua aplicação na solução de problemas e o seu desenvolvimento (significação) são colocados em check, isto é, como objeto da aprendizagem.

É claro que, em tempos da percepção de encurtamento do tempo de acesso a conhecimentos e informações pela rede mundial de computadores (internet), em suas múltiplas linguagens e seus múltiplos recursos audiovisuais, o papel da autonomia do aluno ganha destaque, no contexto de um mundo moderno e atrativo em face a uma Escola atrasada e desinteressante. Não obstante, o acesso à informação e aos conceitos científicos não se reduz ao encontro da sua expressão verbal, memorizada, imobilizada e presa a uma dinâmica associacionista (quase antropoide), pois "no momento da assimilação da nova palavra, o processo de desenvolvimento do conceito correspondente não só não se conclui como está apenas começando" (VIGOTSKI, 2009, p. 394). Antes, o encontro com a palavra é parte do caminho de sua significação.

Embora Vigotski não tenha prescrito os processos posteriores à apresentação do conceito científico, a ZDI (ou scaffolding) parece coroar esse caminho-aprendizagem, uma vez que, ganha ênfase o papel do professor mediador, no intuito de promover a tomada de 
consciência (Claparède), isto é, o uso arbitrário e intencional do conceito, pois, essa transformação ou desenvolvimento rumo à liberdade de pensamento e independência ao campo objetivo ou, no limite, ao enriquecimento da consciência, não aparece de forma inata.

Quando tomamos a especificidade da Educação em Química, também marcada pelo uso de experimentos (fenômenos concretos) com fins pedagógicos, atentamos para as implicações didáticas do fato de os CCie e CCot terem distintas relações para com o objeto, além de diferentes formas de apreensão e de desenvolvimento, pois para Vigotski,

o desenvolvimento de ambos pressupõe a discriminação dos próprios processos intelectuais que lhes servem de base. No processo de ensino o sistema de conhecimentos (CCie), ensina-se à criança o que ela não tem diante dos olhos, o que vai além dos limites da sua experiência atual e da eventual experiência imediata. (Ao passo) que a assimilação dos conceitos científicos (CCie) se baseia igualmente nos conceitos (CCot) elaborados no processo da própria experiência da criança (...) (Vigotski, 2009, p. 268-269 - grifos nossos).

O caráter mediador dos CCot da relação entre CCie e mundo objetivo (por exemplo, o conceito de molécula e uma chaleira expelindo vapor) nos coloca numa crítica à posições que supervalorizam o contato individual com os CCot como estratégia de ascensão mecânica aos CCie, desconsiderando que suas linhas desenvolvimentais são distintas. Podemos dizer que o CCie adentra na ZDI do CCot (espontâneo) de modo a promover seu desenvolvimento ascendente. Isso é permitido pelo fato de que, por caminhos opostos de desenvolvimento, os conceitos científicos e os cotidianos (espontâneos) se manifestam por diferentes formas de funcionamento, aspectos, motivos e intensidade (fraco/forte), mas por formarem uma unidade dialética entre si, têm suas delimitações fluídicas que permitem múltiplas e complexas interações, os levando a transformações mútuas, e não à transmutação de um em outro.

Nessas controvérsias de supervalorização do contato autônomo com a experiência imediata, Yuriy V. Karpov (2003) estabelece, a partir do horizonte vigotskiano, uma crítica aos métodos de ensino construtivistas inspirados em J. Piaget e J. Dewey, denominados de Descoberta Orientada e reavivados nos anos de 1990, porém, herdeiros da Aprendizagem por Descoberta muito popular nas décadas de 1960 e 1970, no contexto norte-americano.

Em comparação com as práticas pedagógicas tradicionais, a motivação (sentido) e o engajamento dos alunos são superiores nessas investigações guiadas, ao passo que, duvidoso é o seu potencial na aprendizagem dos $\mathrm{CCie}$, no sentido de que a consciência reflexiva 
proporcionada pela sua apreensão torna "o pensamento dos estudantes bem mais independente de suas experiências pessoais".

Como tarefa de organizar pedagogicamente momentos que explorem essas características concretas e abstratas (buscando uma abordagem unitária) como meio de manipular os conceitos em sistema, vemos a necessidade de discriminar seus processos, em oposição a uma "pedagogia antropoide" que privilegia e limita-se a direcionar as estratégias ao campo visual (de forma rápida, fácil e passiva) ("ao que se tem diante dos olhos" - exercícios, experimentos, esquemas, fórmulas, equações, definições, cálculos, etc.) em face a perceber, estimular e colocar o pensamento em movimento. Conjecturamos que, para isso, uma radical postura prospectiva e idealizada dos movimentos intencionados pelo professor e mediado pelo material de ensino é essencial, bem como a discriminação de seus possíveis elementos constituintes.

Essa tese vai de encontro com Karpov (2003) ao afirmar que a teoria vigotskiana não está livre de falhas, mas que, subestimou a importância do conhecimento processual para os alunos, ou seja, a consciência do próprio caminho que os levaram ao domínio subjetivo de conceitos. Por outro lado, citando Elkonin, ressalta a centralidade do ensino dos CCie e sua defesa como condição de primeira ordem para o viés vigotskiano (ELKONIN apud KARPOV, 2003, p. 69).

Aqui, nos aproximamos ao afirmar a essencialidade dos conceitos científicos-escolares, onde o desenvolvimento dos CCot não pode mascarar uma falsa apropriação dos CCie e seu uso autônomo, nos afastando, simultaneamente, ao negar a subestimação dos aspectos metodológicos de ensino (instrucionais) e, com eles, os campos dos sentidos e das emoções, não aprofundadas, porém reconhecidos no trabalho de Vigotski. Ainda assim, a partir dessas considerações e mantendo-as, cabe indagar como se daria o conflito entre o tempo rápido da lógica de consumo e o tempo para essa ascensão ao sistema conceitual genérico-abstrato?

Nas sociedades abastadas de hoje, impera, e se alastra, aspectos de uma hipermodernidade essencializadora de relações efêmeras, hedonistas e individualistas (LIPOVETSKY, 2004), assim como, a onipresença do consumismo individualista privilegiador de processos rápidos e fáceis tem fortes implicações na personalidade humana (etos infantilista e identidades como marcas $^{\circledR}$ ) (BARBER, 2009). No que consiste a relação daquelas pedagogizações, marcadas por estratégias emocionais (prazer) e "identitárias" com a perspectiva Histórico-Cultural? 
Referimo-nos ao projeto dos Complete Works (YASNITSKY, 2012, p. 144) e a efervescência dos debates sobre o papel das emoções e da personalidade no sistema vigotskiano. Nas pegadas deixadas pela sua "obra madura" temos que o significado da palavra é parte (mais estável) constituinte do sentido, esse último, na esteira Paulham, sendo "sempre uma formação dinâmica, fluida, complexa, que tem várias zonas de estabilidade variada" (VIGOTSKI, 2009, p. 465). Formam uma unidade dialética a exemplo dos CCot (rico em concretude) e CCie (rico em abstração), pois, a "palavra incorpora, absorve de todo o contexto com que está entrelaçada os conteúdos intelectuais e afetivos e começa a significar mais e menos do que contém o seu significado quando tomamos isoladamente e fora do contexto (...)" (VIGOTSKI, 2009, p. 465-466).

Como porta de entrada para superar um racionalismo cego, nos diz o bielorrusso que, se um pensamento assemelha-se a uma nuvem estática que precipita chuvas de palavras, o "campo da nossa consciência que o motiva, que abrange os nossos pendores e necessidades, os nossos interesses e motivações, os nossos afetos e emoções" (VIGOTSKI, 2009, p. 480), é o vento que a movimenta. Nesse contexto, ganham ênfase os debates sobre o papel da vivência (Переживание - Perejivanie), obviamente, devido a sua importância, se liga, também, a problemas de tradução, conforme Prestes (2010, p. 117), e, com isso, de significação.

Baseadas no trabalho de Vigotski intitulado de "A crise dos sete anos", do livro Psirrologuia razvitia rebionka, edição de 2004, Prestes e Tunes nos dizem que o ambiente não se coloca para o indivíduo de forma plena e absoluta e quando intencionamos investigar o desenvolvimento humano isso ganha ênfase, uma vez que, implica no fato de que "é preciso conhecer o ambiente na sua relação com as especificidades de cada indivíduo. Não existe ambiente social sem o indivíduo que o perceba e o interprete (...)" (PRESTES e TUNES, 2012, p. 333). Por isso resgatam a definição dada por Vigotski:

Perejivanie para a criança é exatamente uma unidade simples, relativa à qual não se pode dizer que represente uma influência do ambiente sobre a criança ou uma especificidade da criança; perejivanie é exatamente a unidade da personalidade e do ambiente, assim como está representada no desenvolvimento. Por isso, no desenvolvimento, a unidade dos aspectos da personalidade realiza-se numa série de perejivanie da criança. Perejivanie deve ser entendida como uma relação interna da criança como pessoa com um ou outro aspecto da realidade (VIGOTSKI apud PRESTES e TUNES, 2012, p. 333). 
Podemos ver, por meio de Toassa (2009), que o termo vivência permeia toda a produção de Vigotski e, não poderia ser diferente, se "desenvolve" desde A tragédia de Hamlet, como oposição ao intelecto inspirado pelo simbolismo russo à Psicologia da Arte. Em Teoría de las emociones... e A questão do meio na pedologia, sob influência dos gestaltistas, por exemplo, a coloca como "unidade sistêmica da consciência, a própria relação interna da consciência/personalidade com o meio, conceito híbrido, em que pessoa e meio se relacionam de modo indivisível" (TOASSA, 2009, p. 27).

Na tarefa árdua de analisar a obra inacabada Teoría de las emociones ..., Costa e Pascual (2012) conjecturam a localização das emoções no plano das funções psicológicas superiores, ao inferirem que, não se reduzindo à herança biológica, na:

(...) trajetória evolutiva, à medida que se desenvolve o aspecto intelectual, as emoções não permanecem invariáveis, mas se integram ao intelecto e a outras funções psíquicas, exercendo influência sobre estas (transformando-as) e, ao mesmo tempo, sendo influenciadas por aquelas (transformando-se na relação) (COSTA e PASCUAL, 2012, p. 632).

Temos, por outro lado, que a emoção não se coloca de forma independente da consciência, sobretudo, incorporada às vivências e seu contexto. Se a palavra aparece no texto sempre integrada a um subtexto, é indício de que ela "está para a consciência como o pequeno mundo está para o grande mundo, como a célula viva está para organismo, como o átomo para o cosmo" (VIGOTSKI, 2009, p. 486).

Aproximando-nos da categoria vivência como unidade integradora da unidade afetointelecto (pensamento e emoção) e mediadora da personalidade e da consciência com o meio (contexto), temos uma possível entrada para a problematização ampliada da noção de tempo (não apenas o tempo físico marcado pelo sinal sonoro entre as aulas, mas um tempo social que integre os sentidos humanos), uma vez que, as "vivências inscrevem-se numa temporalidade de fatos que se estendem no passado, presente e futuro da vida psicológica" (TOASSA, 2009, p. 28).

Nessa mesma direção, a atividade criadora preserva a unidade afeto-intelecto, entendida como "algo nuevo, ya sea cualquier cosa del mundo exterior producto de la actividad creadora o cierta organización del pensamiento o de los sentimientos que actúe y esté presente solo en el proprio hombre (VIGOTSKI, 2012, p. 11- grifos nossos). Por outra, como processo que combina o velho e o novo, é uma síntese mobilizadora de passado, presente e futuro. 
El cerebro no solo es el órgano que conserva y reproduce nuestra experiencia anterior (passado), sino que también es el órgano que combina, transforma y crea a partir de los elementos de esa experiencia anterior las nuevas ideas y la nueva conducta. (...) Es precisamente la actividad creadora del hombre la que hace de él un ser proyectado hacia el futuro, un ser que crea y transforma su presente (VIGOTSKI, 2012, p. 13-14-grifos nossos).

Da reflexão exposta, longe de, forçosamente, pensarmos uma noção de tempo vigotskiana, retiramos subsídios para orientar a problematização do planejamento de recursos didáticos em Química inspirados na perspectiva Histórico-Cultural. Para isso, elaboramos um artefato que pudesse, razoavelmente, auxiliar-nos nessa tarefa.

\section{O planejamento de recursos didáticos de Química nas ações do Pibid}

Em vista da complexidade que caracteriza o campo da Didática, ganha ênfase na formação inicial, mesmo não a tomando como experiência suficiente, a tarefa de auxiliar o futuro-professor a perceber a natureza metodológica e a função social (como fazer/porque fazer) da ação docente. Diante disso, relacionamos as discussões sobre as implicações temporais e o suporte vigotskiano à ação docente no microcosmo da sala de aula, nucleada pela reflexão sobre as estratégias de mobilização de recursos didáticos, ainda que, Vigotski não tivesse descrito "qual processo de domínio de conceitos científicos deveria estar depois de os conceitos terem sido apresentados aos alunos” (KARPOV, 2003, p. 66 - tradução nossa).

A tarefa de produzir e organizar recursos didáticos surgiu como um problema na prática pedagógica de coordenadores de área, professores supervisores e bolsistas de iniciação à docência, uma vez que, a negociação curricular entre uma perspectiva inovadora do Pibid e a organização escolar (submetida a exames periódicos como o SAERJ) situavam os planejamentos num contexto de tensão (de constrangimento e de possibilidades) complexos e relevantes à formação de professores de Química.

Estamos cientes de adentrarmos em mares revoltos, de pedagogias ingênuas, espontaneístas ou diretivistas, entretanto, no contexto de um scaffolding, propusemos um artefato mediador para articular nossa reflexão sobre as ações didáticas materializadas nos planejamentos de ensino, um esqueleto de peixe (fish skeleton) (Figura 1), isto é, provisório 
como um andaime. Em outras palavras, pretende-se como uma primeira visão de conjunto, a qual é, sucessivamente, alterada ou reconstruída visando a unitariedade e coerência interna.



Figura 1: Esquema numa folha do tipo A4 para as anotações. Na região inferior: descrição de artefatos e ações; Na região superior: o efeito desejado correspondente a cada ação-artefato.

Estamos na "fluidez" do fenômeno educativo, aonde a sua complexidadecontraditoriedade afasta qualquer tentativa que o pretenda mecanizar e estruturar seu devir. A água, como um fluido, como pode assumir variadas formas, se molda de acordo com as barreiras do meio para onde flui, porém, uma força ou uma diferença de pressão inicial determina seu fluir, a coloca em movimento para distintas formas assumir. Um fluido em movimento é um fluxo (o que queremos despertar com o fish skeleton, inserido nos mares revoltos da escolarização).

Em The Beat of The System, o historiador Stephen Meyer, em metáfora, vê a linha de montagem formada por córregos interligados, como um grande rio para onde escoam seus afluentes (SINGER, 1994). Frente a esse fluxo de águas tayloristas fordistas (como enxurrada de palavras vazias) da sala de aula é que introduzimos os planejamentos como simples esqueletos (intenções) que podem sustentar (ou constranger) um livre nado contra as correntes. A distribuição do conteúdo teórico que é objeto de reflexão e disparado pelo coordenador de área encontra-se sumarizado e esquematizado abaixo (Figura 02). 


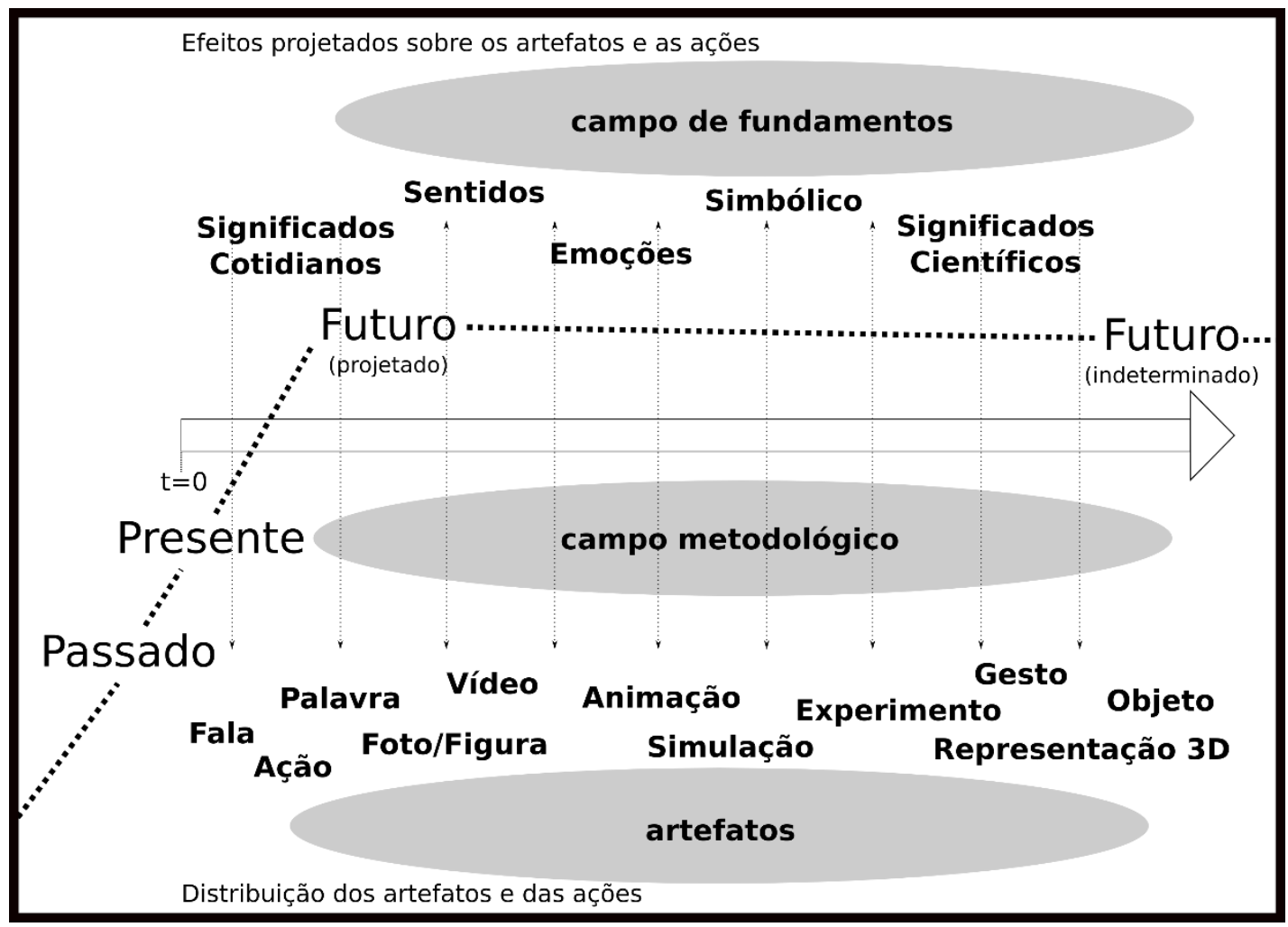

Figura 2: Diferentes aspectos que são objeto de problematização na produção-organização de recursos didáticos em Química

Como o esqueleto, em si, é morto, fóssil, que perde expressão frente ao peixe vivo, na sua plenitude, raramente lembramos de sua sustentação óssea. Sua organicidade é obtida na interação social de alunos e professor, ponto de encontro de sentidos e significados, de aspectos objetivos e subjetivos, diálogos e monólogos, fala e escrita, pensamento e emoção, mediados pela percepção temporal.

Por fim, os planejamentos, então, como mobilização de artefatos e ações não se inscrevem no campo da transmissão mecânica, mas sim, propiciadores de atividades nas quais os alunos possam se apropriar deles por reconstrução criativa. No contexto dos limites e das contradições que caracterizam a sala de aula, no Ensino Médio, é que soltamos (esses fish skeletons) o desafio de pensar a mobilização de artefatos, e analisar pela perspectiva vigotskiana, tentando fisgar as relações temporais envolvidas tornando-as conteúdo para a reflexão sobre o uso de diferentes recursos didáticos em sala de aula.

Podemos referenciar, como produtos desse processo, algumas sequências de recursos didáticos implementadas na disciplina de Química, no âmbito das escolas estaduais parceiras do Pibid - Volta Redonda. Como forma de apresentar um perfil dos materiais produzidos, 
destacamos a sequência intitulada A contaminação do solo no Bairro Volta Grande IV, uma vez que, o bairro onde se localiza a escola parceira do Pibid vem sofrendo desde 2013 com a constatação da contaminação do solo por metais pesados, BTEX, HPA e PCB proveniente do fato de essa área ter sido usada, no passado, como um local de descarte indevido de resíduos industriais da CSN (Companhia Siderúrgica Nacional), sendo que, hoje, comporta um condomínio de residências populares.

Trazer esse tema para a sala de aula e integrá-lo de forma coerente e unitária ao currículo escolar se mostrou um desafio e para o qual o referido artefato se mostrou satisfatório, sobretudo na organização de diferentes tipos de recursos didáticos e a atribuição de suas respectivas funções metodológicas, em especial, nos inspiramos nas recomendações expressas nos conceitos de Três Momentos Pedagógicos (GEHLEN, MALDANER e DELIZOICOV, 2012) e nas Sequências de Ensino Investigativas (CARVALHO, 2013).

Assim, partimos de duas perguntas iniciais: Em nosso bairro Volta Grande, todas as quintas-feiras na Rua 1050, é realizada uma das etapas itinerantes da Feira Livre de Volta Redonda. Se formos comparar as hortaliças comercializadas na feira e aquelas comercializadas nos supermercados da cidade, quais diferenças seriam encontradas? Quais são os fatores que você acha importante para a qualidade dos alimentos cultivados? Anteriormente, os bolsistas do Pibid fizeram registro fotográfico da feira e as questões iniciais se deram a partir dessas fotos.

Depois de um debate e da organização e registro das respostas dos alunos, implementamos dois experimentos: a) a coloração de uma rosa branca a partir da imersão de seu caule dividido ao meio e, separadamente, em água e em água com corante alimentar. Quando a rosa estava cerca de 10 minutos com uma parte do caule imersa no corante, ela começou a adquirir a coloração azul, como veias. Após esperar os 20 minutos necessários, uma parte da rosa tornou-se totalmente azul, a cor do corante, e a outra metade da flor manteve-se branca. No final da primeira tarefa havia a seguinte pergunta: $O$ que explica as alterações encontradas na flor?

Com esse experimento, intencionamos fazer com que os alunos observassem que a substância capaz de ser dissolvida em água pode, também, ser absorvida pela planta. Outro aspecto explorado foi o tubo com o corante alimentício azul, pois nele a sua absorção ficava "visualmente" evidente pela sua deposição nas pétalas da flor, enquanto que, na parte que havia 
apenas água também estava ocorrendo a absorção, porém, "não podíamos ver". Uma das entradas para a elevação conceitual rumo a abstração típica dos modelos teóricos da Química.

Anteriormente, lembramos os alunos de observarem, também, a possível variação de volume dos líquidos em cada tubo, com o passar do tempo. Assim, como o corante, muitas substâncias tóxicas, quando descartadas indevidamente no meio ambiente, podem ser absorvidas e contaminar hortaliças, árvores frutíferas, etc. sendo na maioria das vezes impossíveis de serem vistas ou detectadas.

Num segundo experimento, tivemos b) a condutividade elétrica de amostras de areia, terra preta, corante, sal de cozinha e sacarose, ambos, primeiro, na forma sólida e, em seguida, misturados com água morna. No final da segunda tarefa havia a seguinte pergunta: Como vocêe explica o fato de que na presença de água algumas amostras conduziram eletricidade e outras não? (Utilize seus conhecimentos para descrever e explicar o que aconteceu em cada amostra. O sal de cozinha, o corante e a terra preta (terra de jardim, obtida comercialmente) apresentaram condutividade elétrica devido à solubilidade e à formação de íons livres na solução, contudo a sacarose, também solúvel, não conduz, por ser um composto molecular que não se ioniza, mas se solubiliza em água por meio de ligações de hidrogênio.

A areia apresentou um fenômeno importante que, também, foi ressaltado no momento de apresentação e da construção coletiva dos conceitos químicos envolvidos, ou seja, os alunos esperaram que, no caso da areia em água, a condutividade não se processasse, pelo fato de ela ficar depositada no fundo do recipiente e não se dissolver como o sal de cozinha formando uma mistura homogênea.

A areia é composta em sua maior parte por sílica, formando uma enorme cadeia polimérica e, assim, torna-se insolúvel em água e não condutora de eletricidade, entretanto, a água desse sistema (nossa amostra de areia + água) pode ter uma baixa condutividade pelo fato de, assim como os outros tipos de solo, ser uma "grande mistura", ou seja, podem existir substâncias solúveis e formadoras de íons em solução. Esse aspecto do experimento foi bastante rico e produziu muitas discussões. Ele ajuda aos alunos a perceberem que os diferentes tipos de solos absorvem componentes do meio, inclusive potenciais substâncias poluentes.

Posteriormente, usamos um texto Paradidático contendo conceitos de poluição dos solos, transpiração de plantas, ligações químicas e a exploração de moléculas no estudo das funções orgânicas. Concomitantemente, usamos recursos digitais para articular a linguagem verbal (texto escrito e fala) com a linguagem visual (por meio de fotos, figuras, vídeos e 
animações) no intuito de criar mediadores para a construção de conceitos científicos envolvidos na transpiração das plantas e na água capilar (num diálogo com o campo da disciplina de Biologia) e aqueles relativos a disciplina de Química, num processo que relacionava cada aspecto concreto observado ao seu correspondente conceito científico abstrato.

Como tarefa de avaliação foi exibida, em vídeo, uma reportagem sobre o problema da contaminação no bairro e, logo, estabeleceu-se um debate sobre os conhecimentos químicos estudados e a sua aplicação nesse problema ambiental, remetendo a um olhar ressignificante dos momentos anteriores, uma vez que, se envolveram, emocionalmente, quando emergiram os debates sobre, a perda da praça (que foi concretada, por medida de segurança) e a eventual perda das moradias, num quadro de possível remoção, provocado pelo aumento do grau de toxicidade.

Outros planejamentos foram elaborados, dos quais destacamos, a seguir, seus aspectos gerais em termos de ações e artefatos utilizados. Para o ensino do tópico curricular modelos atômicos de Thomson e Bohr iniciamos com um experimento inicial que mostrava os diferentes comportamentos de um monitor de tubo e um monitor de LCD frente à ação de um imã, visando levantar a discussão e os conhecimentos prévios dos alunos. A pergunta inicial ( $O$ que explica o fato de, quando uma mesma imagem colorida é projetada em um monitor com tecnologia de Tubo e em outro do tipo LCD, essa mesma imagem apresentar diferentes comportamentos frente à ação de um imã?) tinha como objetivo relacionar o tubo do monitor com o tubo de Crookes e sua função histórica na elaboração teórica do modelo de Thomson.

Partindo para dois experimentos: a) geração de eletrostática por atrito, usando caneta de plástico e pedaços pequenos de papel (CCot), o qual teve como objetivo retratar a natureza elétrica da matéria (CCie) (necessária para o modelo de Thomson) e b) a observação de diferentes amostras do cotidiano (sabão em pó, colírio oftálmico, água tônica, água, álcool, corante alimentício verde e extrato de folhas de plantas verde) frente às lâmpadas UV, amarela, verde, vermelha, anti-insetos e a luz visível para constatar o fenômeno da fluorescência (CCot) (necessária para relacioná-la às transições eletrônicas (CCie), ou seja, com o modelo quântico de Bohr).

A espinha de peixe nos ajudou a explorar a diferença entre o corante verde e o extrato verde, pois as suas aparências na luz visível (ambos de cor verde) não são suficientes para explicar a emissão da cor vermelha apenas do extrato, mediante a luz negra. Como um convite a elaborações conceituais abstratas. As diferenças tecnológicas entre Tubo e LCD também 
procuraram se inserir no mundo (emocional) dos adolescentes, hoje, cercados por mudanças tecnológicas (de LED à OLED) nas telas de seus celulares, tablets e computadores. Ainda nos valemos de um vídeo com o funcionamento do tubo de Crookes, simulações dos modelos atômicos (do projeto PhET - Interactive Simulations) e textos paradidáticos.

O PPP de uma das escolas parceiras demandou o tema Saúde, uma vez que, foi detectada a prática de bullying sobre a estética corporal de alguns alunos. Elaboramos um planejamento que abordasse o uso corantes nos alimentos. Como pergunta inicial escolhemos: Quais são os principais aspectos que você considera importantes ao comprar alimentos no supermercado? Servindo para criar um diálogo e explorar os conhecimentos prévios dos alunos em relação a qualidade, ao sabor e ao papel do aspecto visual dos alimentos.

Para auxiliar no processo de motivação e de direcionamento dos alunos à questão inicial, apresentamos uma imagem em preto e branco retratando uma porção de morangos, tentando explorar seus sentidos para os alunos. Posteriormente, a mesma imagem apareceu com suas cores originais, impulsionado o diálogo sobre o aspecto visual. Esse processo procurou "esticar o tempo" desses questionamentos (da interação), o qual, por vezes, em sala de aula, fica reduzido a um jogo mecânico de perguntas binárias que levam a uma resposta rápida, sempre "correta" ou "errada".

A seguir, propomos dois experimentos: a) cromatografia em papel de corantes extraídos da cobertura de confeitos de chocolate com o intuito de encaminhar as discussões para a "natureza da matéria", para o seu "interior", tentando fazer surgir ideias de senso comum como material, essência, substância, etc. (CCot). Aqui, o que se separam na cromatografia são substâncias e não “cores”, nesse caso são as moléculas orgânicas (CCie) que pela sua interação com a luz visível (matéria-energia), produzirão o fenômeno da cor.

O nosso esquema ajudou a explorar o uso de amostras de cor verde que se separavam nas cores amarela e azul e uma amostra de confeito de cor azul que, nesse experimento, "não se separava de outra cor". Novamente, um caminho menos antropoide (associativo/limitado ao campo visual) e mais intelectual-abstrato era necessário para pensar: de onde vem a cor?

Noutro experimento, b) a adsorção de corante alimentício (duas gotas de corante vermelho em $5 \mathrm{~mL}$ de água) utilizando carvão ativado (usado no interior de geladeiras) e bagaço de coco verde (mesocarpo), com o objetivo de relacionar o desaparecimento da coloração vermelha (CCot) com os conceitos de molécula e de interações intermoleculares (CCie) entre o carvão/mesocarpo (carbono-carbono) e o corante adsorvido. 
A construção dialogada dos modelos teóricos da Química seguiu orientada por um texto paradidático (contendo a função química dos corantes, o mecanismo dos pigmentos e estudos sobre a redução da contaminação por corantes). Foram utilizados um vídeo para simular o funcionamento do carvão ativado em filtros de ar e outro vídeo que relatava casos de pessoas que apresentaram alergia ao ingerir alimentos contendo corantes artificiais, isto é, com a intenção de refletir sobre o cuidado com a ingestão de alimentos industrializados e seus corantes alimentícios, algo que, por vezes, escapa à rapidez necessária a uma prática consumista.

Buscamos explorar fenômenos de longa escala de tempo com um planejamento referente à acidificação dos oceanos por emissões antropogênicas de $\mathrm{CO}_{2}$. Partimos de uma tríade de fotos representando a poluição no oceano (objetos sobrenadantes), corais e a concha parcial de um molusco marinho. O diálogo iniciou tentando explorar os sentidos e os significados atribuídos a cada figura e, depois, as possíveis relações existentes (ou elaboradas) entre cada uma delas. Ampliando o tempo e fomentando o debate, foi introduzido a leitura de um pequeno texto descrevendo, de forma sucinta, o impacto ambiental e econômico gerado nos oceanos pelo aumento da emissão de dióxido de carbono.

O debate intencionava criar um "clima" para colocar as perguntas: a) Como essa poluição nos oceanos pode estar relacionada ou não com nossas ações aqui na escola ou em nossa cidade? b) como o gás dióxido de carbono existente na atmosfera consegue provocar a morte de crustáceos no fundo dos oceanos?

Após isso, propomos a realização de experimentos sistematizadores do conhecimento a) usando a mesma quantidade de vinagre (incolor) foi observado, separadamente, sua ação frente a casca de ovo, concha, giz escolar e bicarbonato (produto alimentício). Aqui, os alunos explicam com suas palavras as semelhanças e as discrepâncias observadas, fato que faz com que, em todos os experimentos, instaure-se uma disputa para "frear a rapidez do olhar o cotidiano" e fomentar um "aprender a observar um fenômeno", com a cautela e a continuidade requerida. A deterioração dos materiais (CCot) e a eliminação de gases (CCot) são necessários aos conceitos de reação ácido base presentes na descalcificação (CCie) que leva a morte de crustáceos (altera os ecossistemas marinhos), bem como, na produção de $\mathrm{CO}_{2}$ (CCie).

Numa segunda etapa, foram preparadas quatro soluções com carbonato de cálcio $\left(\mathrm{CaCO}_{3}\right)$, todas contendo fenolftaleína, acrescentando-se, separadamente, sopro com um canudo, injeção de ar com uma seringa e, no último, acoplou-se o produto gasoso obtido pela reação do bicarbonato com o vinagre (um sistema a parte foi montado previamente). Aqui, a 
alteração da cor da fenolftaleína por “diferentes ares” (CCot) são necessárias para o estudo da formação do ácido carbônico $\left(\mathrm{H}_{2} \mathrm{CO}_{3}\right)$ a partir do gás carbônico $\left(\mathrm{CO}_{2}\right)$ (CCie). Ao acrescentarmos o sopro, procuramos colocar o gás carbônico, também, como uma substância emitida naturalmente (emissões biogênicas) face a uma leitura reducionista de substância "química” (e química num sentido nocivo), usada para emissões antropogênicas (pela queima de combustíveis fósseis, por exemplo).

Usamos também um texto paradidático e uma animação retratando o mecanismo de acidificação dos oceanos (com representações atômico-moleculares) a partir das emissões de gás carbônico. Nesse planejamento, procuramos aproximar o tempo das transformações geoquímicas (décadas para o aumento do pH dos oceanos) do tempo de fenômenos cotidianos como a emissão de gases de uma siderúrgica ou de veículos automotivos, de forma a buscar uma visão mais integrada dos fenômenos químicos locais e globais.

Tentamos explorar os fenômenos relativos à vitamina $\mathrm{C}$ compreendendo sua função nutricional e seu uso em cosméticos, sendo esse último, potencialmente, ligado ao cotidiano das jovens adolescentes. Primeiramente, numa etapa i), propomos o uso de fragmentos do filme 1492: A conquista do Paraíso (dirigido por Ridley Scott) e figuras representando mapas do século XV e XVI para retratar as grandes navegações e o contorno do Cabo da Boa Esperança. Também, ampliando o tempo de discussão, insere-se a leitura de um breve texto escrito descrevendo o ambiente das embarcações, a dieta alimentar, o tipo de trabalho, o tempo de navegação e os sintomas da doença denominada de "o mal da Angola".

O diálogo e a troca dos sentidos e significados disparados pelo "retorno ao passado" tenta criar um ambiente favorável para a pergunta: como você explicaria o fato de os marinheiros adoecerem e morrerem, mesmo se alimentado durante as viagens?

Num texto paradidático trazemos aspectos da viagem do explorador português Vasco da Gama, o qual, ao contornar a ponta da África, em 1497, teve 2/3 de sua tripulação morta pelo mal da Angola. Após o debate temos a etapa ii), na qual, realizamos experimentos envolvendo a fruta maçã em diferentes situações: inteira, fatiada e com suco de limão em sua superfície, fatiada e com vitamina $\mathrm{C}$ em pó em sua superfície, fatiada e embalada a vácuo com plástico transparente. Essas amostras são expostas: à luz ambiente e à ausência de luz (numa caixa protetora). $\mathrm{O}$ esqueleto de peixe nos ajudou a escolher as variáveis pertinentes (fatores determinantes: luz ambiente, ar, a ausência de luz, ausência de ar e vitamina C), para ligar aos CCie correlatos. 
Ao cortamos a maçã e deixarmos a mesma exposta à luz e ao ar (CCot) podemos perceber que a mesma escurece (CCot), fato esse que se deve à formação da melanina (CCie), sofrendo ação direta do oxigênio (CCie) e da luz. No caso da presença de suco de limão e vitamina C em pó, em contato direto sobre a superfície da maçã, não há o escurecimento (CCot), isso deve-se ao fato de acontecer, primeiramente, a degradação da vitamina $\mathrm{C}$ presente no suco de limão e no pó (CCie) formando o ácido L-dehidroascórbico.

No ambiente sem oxigênio (embalada à vácuo) e sem luz (colocada dentro de uma caixa) ocorre um pequeno, mas perceptível escurecimento (CCot), evidenciando que a presença de oxigênio e luz acelera o processo de formação da melanina (CCie).

Na etapa seguinte, iii) propomos um texto paradidático constituído por: breve histórico da doença escorbuto (mal da Angola) e da vitamina C, função da vitamina C na alimentação e no uso em cosméticos. Para complementar o texto paradidático, é proposto a exibição de dois vídeos, um, relacionando a importância da vitamina C para a nutrição humana e, o outro, mostrando sua função em cosméticos para a pele (cremes e hidratantes anti-idade).

\section{Algumas considerações}

Ao longo do uso desse artefato na elaboração de distintas propostas de sequência de recursos didáticos em Química pudemos constatar que a ideia de aproximar as problematizações sobre o tempo dentro de uma perspectiva Histórico-Cultural é promissora pelo fato de: i) explorar a multimodalidade por meio do uso de distintos recursos; ii) por buscar um olhar relacional entre cada artefato ou ação projetada; iii) por trazer ao planejamento os aspectos emocionais junto aos intelectuais; e iv) por auxiliar a perceber o planejamento como processo provisório e complexo. Quanto às noções de tempo, pôde-se avançar numa compreensão do encadeamento das ações e artefatos internos à sala de aula, nos remetendo a explorar as possibilidades de ações externas à escola, porém, nesse mesmo quadro integral (mediadas por TIC, por exemplo).

Entretanto, essas vivências nos orientam para uma análise mais profunda e longitudinal do uso dessa abordagem, pois romper com uma "pedagogia antropoide" que não se orienta para a elevação cultural das massas populares, atentando para suas dificuldades e especificidades, não se coloca como tarefa fácil, por isso, podemos afirmar, apenas, que estamos dando os primeiros passos nessa direção. 


\section{Referências}

ABBAGNANO, N. Dicionário de Filosofia. São Paulo: Martins Fontes, 2007.

BARBER, B. R. Consumido... Rio de Janeiro: Record, 2009.

CARVALHO, A. M. P. de O ensino de Ciências e a proposição de sequências de ensino investigativas. In: CARVALHO, A. M. P. de (Org.) Ensino de Ciências por Investigação: condições para implementação em sala de aula. São Paulo: Cengage, 2013.

CARVALHO, E. R. de. Norbert Elias frente aos desafios de superação da aporia entre tempo físico e tempo social. In: Anais do VI Seminário Brasileiro de História da Historiografia p. 01-12, 2012. Disponível em: <http://zip.net/bjtnv2> Acesso em: 15 abr. 2014.

CHAIKLIN, S. The Zone of Proximal Development in Vygotsky's Analysis of Learning and Instruction In: KOZULIN, A. et al. (Orgs) Vygotsky's Educational Theory in Cultural Context. New York: Cambridge, 2003.

COSTA, A. J. A.; PASCUAL, J. G. Análise sobre as emoções no livro Teoría de las emociones (Vigotski). Psicologia \& Sociedade v. 24, n. 3, p. 628-637, 2012.

CRARY, J. 24/7 - Capitalismo tardio e os fins do sono. 1. ed. São Paulo: Cosac Naify, 2014.

DANIELS, H. Vygotsky e a Pesquisa. São Paulo: Loyola, 2011.

DELIZOICOV, D. e ANGOTTI, J. A. Metodologia do Ensino de Ciências. São Paulo: Cortez, 1990.

ELIAS, N. Sobre o tempo. Rio de Janeiro: Zahar, 1998.

GEHLEN, S. T.; MALDANER, O. A.; DELIZOICOV, D. Momentos pedagógicos e as etapas da situação de estudo: complementaridades e contribuições para a educação em ciências.

Ciência \& Educação v. 18, n. 1, p. 1-22, 2012.

KARPOV, Y. V. Vygotsky's Doctrine of Scientific Concepts: Its Role for Contemporary Education In: KOZULIN, A. et al. (Orgs) Vygotsky's Educational Theory in Cultural Context. Reino Unido: Cambridge, 2003.

LEMKE, J. Multimodality, Identity, and Time. In: JEWITT, C. The Routledge Handbook of Multimodal Analysis. London: Routledge, 2009. p. 140-150.

LEMKE, J. Across the scales of time: artifacts, activities, and meanings in ecosocial systems. Mind, Culture, and Activity, 7(4), 2000. p. 273-290.

LIPOVETSKY, G. Os tempos Hipermodernos. São Paulo: Barcelona, 2004. 
PRESTES, Z. R. 80 anos sem Lev Semionovitch Vigotski e a arqueologia de sua obra.

Revista Eletrônica de Educação v. 8, n. 3, p. 5-14, 2014.

PRESTES, Z. R. Quando não é quase a mesma coisa: análise de traduções de Lev

Semionovitch Vigotski no Brasil - Repercussões no campo educacional. Doutorado - UnB, Brasília, 2010.

PRESTES, Z. R. e TUNES, I. A trajetória de obras de Vigotski: um longo percurso até os originais. Estudos de Psicologia v. 29, n. 3, p. 327-340, 2012.

SINGER, H. The beat of the System. [S.1.]: BBC Television, 1994

TOASSA, G. Emoções e vivências em Vigotski: investigação para uma perspectiva histórico-cultural Instituto de Psicologia - USP - Tese de Doutorado - São Paulo, 2009. 348 p.

VIGOTSKI, L. S. A construção do pensamento e da linguagem. 2. ed. São Paulo: Martins Fontes, 2009.

VIGOTSKI, L. S. Imaginación y creación en la edad infantil. 2. ed. Lanús Oeste: Nuestra América, 2012.

VIGOTSKY, L. S. Teoría de las emociones: estudio histórico-psicológico Madrid: Akal, 2004.

YASNITSKY, A. The Complete Works of L.S. Vygotsky: PsyAnima Complete Vygotsky project. Dubna Psychological Journal n. 3, p. 144-148, 2012.

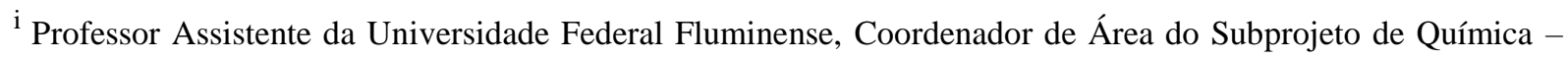
Volta Redonda do Pibid-UFF.

ii Professora Adjunta da Universidade Federal Fluminense, Coordenadora de Área do Subprojeto de Química Volta Redonda do Pibid-UFF.

iii Nos referimos ao enquadramento do tempo em sala de aula às exigências de avaliações externas, como o SAERJ e SAERJinho, em vez de se ajustar ao ritmo de aprendizagem e de vivências dos alunos.
} 